Geront. clin. 1959;1:321

\title{
British and Canadian Medical Associations
}

Joint Annual Meeting

Problems of an Ageing Community

One of the two plenary sessions of the Joint Annual Meeting of the British and Canadian

Medical Associations, in Edinburgh, in July, 1959, was devoted, at the request of the Canadian

Medical Association, to "Problems of an Ageing Population". Sir Arthur Thomson

(Birmingham) was in the chair and the speakers were Professor P. L. Krohn (Birmingham), Dr. J.

H. Sheldon (Wolverhampton), Professor M. Roth (New-castle-on-Tyne), Dr. W. Ferguson

Anderson (Glasgow) and Dr. T. N. Rudd (Southampton).

Professor Krohn pointed out the different rates of ageing of individual systems of the body and mentioned ways of isolating factors responsible for age-changes. He reported the successful preservation of grafted skin, so that an individual tissue has been given a longevity of more than $25 \%$ in excess of the maximum life-span of the intact animal. He concluded that postponing of ageing will confront the physician of the future with a wholly new pattern of disease. Dr.

Sheldon discussed demographic and social aspects of ageing, and stressed that until 70 years of age older people are donors rather than debtors to society and that the hard core of the problem only arises with people of over 75 . He was unable to find any evidence of weakening of family ties and enunciated the principle of "elevating the family into a place of recognized partnership". The Mental Health Problem was discussed by Professor Roth, who also emphasized the community-value of old people in transmitting knowledge of household crafts and favourably influencing happy family relationships. While some mental changes are inherent to old age, others were peculiar to cultures which over-valued youthfulness and denied opportunity to old age. A closer integration of general medical and psychiatric services for the elderly was necessary. Dr. W. F. Anderson reported the results of seven years' work in the Rutherglen Consultative Health Centre, where apparently-healthy old people can have investigation of minor complaints, with a view to maintaining positive health and to detecting disease in its earliest, treatable phases. In Dr. Anderson's words, the experiment projects "the geriatric unit into the ambit of the local authority in a joint effort to prevent illness and to keep people active and healthy in their own homes”. Dr. Rudd mentioned factors in developing a geriatric service from small beginnings, and showed the necessity for a geriatric team. Optimum results can only be obtained by an early home visit to the patient by the physician and his medical-social worker. The prevention of relapse after hospital care remains one of the most difficult problems in geriatrics. 